\title{
Photolysis of trenbolone acetate metabolites in the presence of nucleophiles: Evidence for metastable photoaddition products and reversible associations with dissolved organic matter
}

Nicholas C. Pflug, ${ }^{* 1}$ Andrew K. Kral, ${ }^{2}$ Madeline K. Hankard, ${ }^{3}$ Kathryn C. Breuckman, ${ }^{3}$ Edward P. Kolodziej, ${ }^{4,5}$ James B. Gloer, ${ }^{1}$ Kristine H. Wammer, ${ }^{3}$ and David M. Cwiertny*2

${ }^{1}$ Department of Chemistry, University of Iowa; Iowa City, IA 52242, USA

${ }^{2}$ Department of Civil and Environmental Engineering, University of Iowa; Iowa City, IA 52242, USA

${ }^{3}$ Department of Chemistry, University of St. Thomas; St. Paul, MN 55105, USA

${ }^{4}$ Interdisciplinary Arts and Sciences, University of Washington; Tacoma, Tacoma, WA 98402 USA

${ }^{5}$ Department of Civil and Environmental Engineering, University of Washington; Seattle, WA 98195 USA

*Co-Corresponding Authors:

Nicholas C. Pflug

Email: nicholas.pflug@usys.ethz.ch; Phone: +410789750161

Institute of Biogeochemistry and Pollutant Dynamics

ETH Zurich

Universitaetstrasse 16

8092 Zurich Switzerland

David M. Cwiertny

Email: david-cwiertny@uiowa.edu; Phone: 319-335-1401

Department of Civil and Environmental Engineering

4136 Seamans Center

Iowa City, IA 52242

Prepared for Environmental Science \& Technology

September 1, 2020

Contents: Materials \& Methods, 9 Figures, 10 Pages 


\section{SUPPLEMENTAL MATERIALS AND METHODS}

Reagents. Photolysis experiments used 17 $\alpha$-trenbolone (Australian Government National Measurement Institute; $\geq 98 \%$ ), 17 $\beta$-trenbolone (Sigma; $\geq 98 \%$ ), trendione (Waterstonetech; 99.8\%), sodium azide (Fisher Scientific; 99\%), sodium thiosulfate (Fisher Scientific; 99\%), hydroxylamine (Fisher Scientific; $\geq$ 96\%), ammonium hydroxide (Fisher Scientific; 29.5\% w/w\%), Fluka humic acid (Fluka Chemie GmbH), anhydrous potassium phosphate monobasic $\left(\mathrm{KH}_{2} \mathrm{PO}_{4}\right.$; RPI; ACS grade) and deionized water (Millipore, Q-Grad 2). HPLC analysis used deionized water (Millipore, Q-Grad 2) and acetonitrile (Fisher Scientific; ACS HPLC grade) as the mobile phase.

Photolysis Experiments. A majority of experiments were conducted using a commercially available $1000 \mathrm{~W}$ xenon arc lamp (Newport Corporation). The light was first passed through a water filter to remove IR radiation, reflected off a $90^{\circ}$ full reflectance beam turning mirror, and then passed through an AM 1.5 filter and a $305 \mathrm{~nm}$ long-pass filter to generate a spectrum of light more closely resembling that available at the earth's surface. Lamp irradiance $\left(1662 \mathrm{~W} / \mathrm{m}^{2}\right)$ for wavelengths greater than $305 \mathrm{~nm}$ was measured with a spectroradiometer (ILT950; International Light Technologies, Peabody, MA) at reactor height. Experiments were conducted in a water-jacketed, borosilicate photoreactor ( $37 \mathrm{~mm}$ inner diameter $\times 67 \mathrm{~mm}$ depth for a nominal volume of $\sim 50 \mathrm{~mL}$; Chemglass), whose contents were mixed via a magnetic stirrer and stir plate. Reactors were loaded with $20 \mathrm{~mL}$ of $25 \mathrm{mM}$ potassium phosphate buffer ( $\mathrm{pH} 5,7$, or 9), an initial aqueous steroid concentration of $25 \mu \mathrm{M}(\sim 7-8 \mathrm{mg} / \mathrm{L}$; from freshly prepared $10 \mathrm{mM}$ methanolic stock solutions, $0.25 \% \mathrm{v} / \mathrm{v}$ $\mathrm{MeOH}$ dosed), and an initial aqueous nucleophile concentration of $1 \mathrm{mM}(\sim 30-160 \mathrm{mg} / \mathrm{L}$; from freshly prepared aqueous stock solutions). We note that the concentration of $\mathrm{MeOH}$ cosolvent is higher than the aqueous nucleophile concentration used in these experiments, however $\mathrm{MeOH}$ had no observable effect on kinetics or product distributions here or in our 
previous studies. DOM experiments used an initial aqueous Fluka humic acid (HA) concentration of $5 \mathrm{mg} / \mathrm{L}$ from freshly prepared aqueous stock solutions. HA stock solutions $(\sim 150 \mathrm{mg} / \mathrm{L})$ were prepared by dissolving known masses into deionized water adjusted to $\mathrm{pH}$ 10 using $5 \mathrm{M} \mathrm{NaOH}$. The mixture was then adjusted to $\mathrm{pH} 7$ using $5 \mathrm{M} \mathrm{HCl}$ and subsequently diluted to $5 \mathrm{mg} / \mathrm{L}$ for photolysis experiments. The system temperature $\left(\sim 20{ }^{\circ} \mathrm{C}\right)$ was held constant via a recirculating water bath. Upon irradiation, samples were withdrawn periodically over time to monitor the concentration of the parent TBA metabolite and any detectable transformation products via HPLC analysis. At the conclusion of photolysis experiments, the photolyzed solutions were placed in amber vials and stored in the dark at 20 or $50{ }^{\circ} \mathrm{C}$ to monitor photohydrate stability and TBA metabolite regeneration. Analysis of dark control solutions of parent metabolites showed no observable loss over multiple days.

A subset of experiments (i.e., TBO kinetics with azide) were conducted using a commercially available Atlas Suntest CPS + solar simulator equipped with a xenon lamp and an Atlas UV Suntest filter to provide an emission spectrum accurately simulating that of natural sunlight and an irradiance of $500 \mathrm{~W} / \mathrm{m}^{2}$ (or $\sim 2 / 3$ of the anticipated irradiance at summer solar noon at mid-latitudes $)$. TBO solutions $(25 \mu \mathrm{M} ; \sim 7 \mathrm{mg} / \mathrm{L})$ in $25 \mathrm{mM}$ potassium phosphate buffer (7 mL; pH 5, 7, or 9) and an initial aqueous azide concentration of 1-20 mM ( 65-1300 mg/L; from freshly prepared aqueous stock solutions) were placed in quartz test tubes (10 cm length, 11 and $12 \mathrm{~mm}$ internal and external diameter, respectively) and the test tubes were held at a $45^{\circ}$ angle. Photolysis time varied between experiments, and samples were taken periodically. At the conclusion of photolysis experiments, aliquots of the photolyzed solution were placed in amber vials and stored in the dark for up to five days, or until no more regeneration of TBO was observed.

Analytical Methods. High Performance Liquid Chromatography (HPLC): Samples were analyzed by HPLC for reaction progress with an Agilent 1200 series HPLC-Diode 
Array Detector (DAD) system. The method used an Agilent Zorbax Eclipse XDB-C 18 (4.6 x $150 \mathrm{~mm}, 3.5 \mu \mathrm{m})$ column with acetonitrile/water gradient elution $(1 \mathrm{~mL} / \mathrm{min})$ and scanning 200-400 nm wavelength detection, which also allowed for measurement of UV spectra for all compounds.

Liquid Chromatography High-Resolution Mass Spectrometry (LC-HRMS): LCHRMS data were obtained using a Waters Premier Q-TOF instrument, the same chromatographic method as listed above (HPLC-DAD) with the addition of a $0.1 \%$ formic acid solution and collected using a reference standard of Leu-enkaphalin and positive electrospray ionization over a mass range of 120-1000 Da under the following instrument parameters: $20 \mu \mathrm{L}$ injection volume; $2.8 \mathrm{kV}$ capillary, $35.0 \mathrm{~V}$ sampling cone, $4.0 \mathrm{~V}$ extraction cone and $2.0 \mathrm{~V}$ ion guide voltages; $110{ }^{\circ} \mathrm{C}$ source temperature and $400{ }^{\circ} \mathrm{C}$ desolvation temperature. 


\section{SUPPLEMENTAL RESULTS AND DISCUSSION}<smiles>CC(=O)OC1CCC2C3CCC4=CC(=O)CCC4=C3C=CC12C</smiles>

trenbolone acetate<smiles>[R]C1CCC2C3CCC4=CC(=O)CCC4=C3C=CC12C</smiles>

trenbolone acetate metabolites

$17 \alpha-\mathrm{TBOH}:-\mathrm{R}=\ldots \mathrm{OH}$

17$\beta-\mathrm{TBOH}:-\mathrm{R}=-\mathrm{OH}$

TBO: $-\mathrm{R}==\mathrm{O}$<smiles>[R]C1CCC2C3CCC4=C(CCC(=O)C4)C3=C[C@H](O)[C@H]12</smiles><smiles>[R]C1CCC2C(C=C)=C3CCC(=O)CC3(O)CCC12</smiles>

12- and 5-hydroxy photohydrates

Proposed photonucleophilic addition products for $17 \beta-\mathrm{TBOH}$

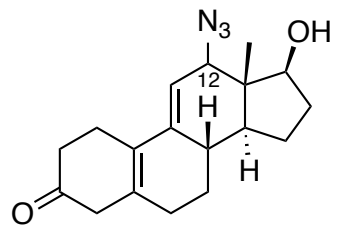

azide product

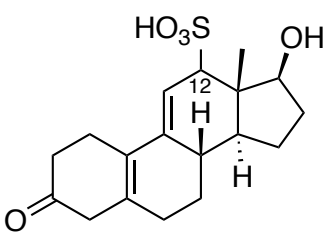

thiosulfate product (bisulfite addition)<smiles></smiles>

ammonia products<smiles>CC12C=CC3=C4CCC(=O)C[C@]4(N)CC[C@H]3C1CCC2O</smiles>

$\mathrm{NH}_{2}$

Proposed nucleophilic substitution products for $17 \beta-\mathrm{TBOH}$<smiles>C[C@H]1C=C2C3=C(C[C@H](O)CCCO)CCC23CCC(=O)C1</smiles><smiles>CC12C=CC3=C4CCC(=O)C[C@]4(N)CC[C@H]3C1CCC2O</smiles>

hydroxylamine products

Figure S1. Structure of trenbolone acetate (TBA), TBA metabolites, 12- and 5-hydroxy photohydrates, proposed photonucleophilic addition products for $17 \beta-\mathrm{TBOH}$, and proposed nucleophilic substitution products for $17 \beta-\mathrm{TBOH}$. TBO and $17 \alpha-\mathrm{TBOH}$ are suspected to form the same products as shown for $17 \beta-\mathrm{TBOH}$, with the exception of azide and bisulfite addition occurring at position C-5 for $17 \alpha-\mathrm{TBOH}$. 


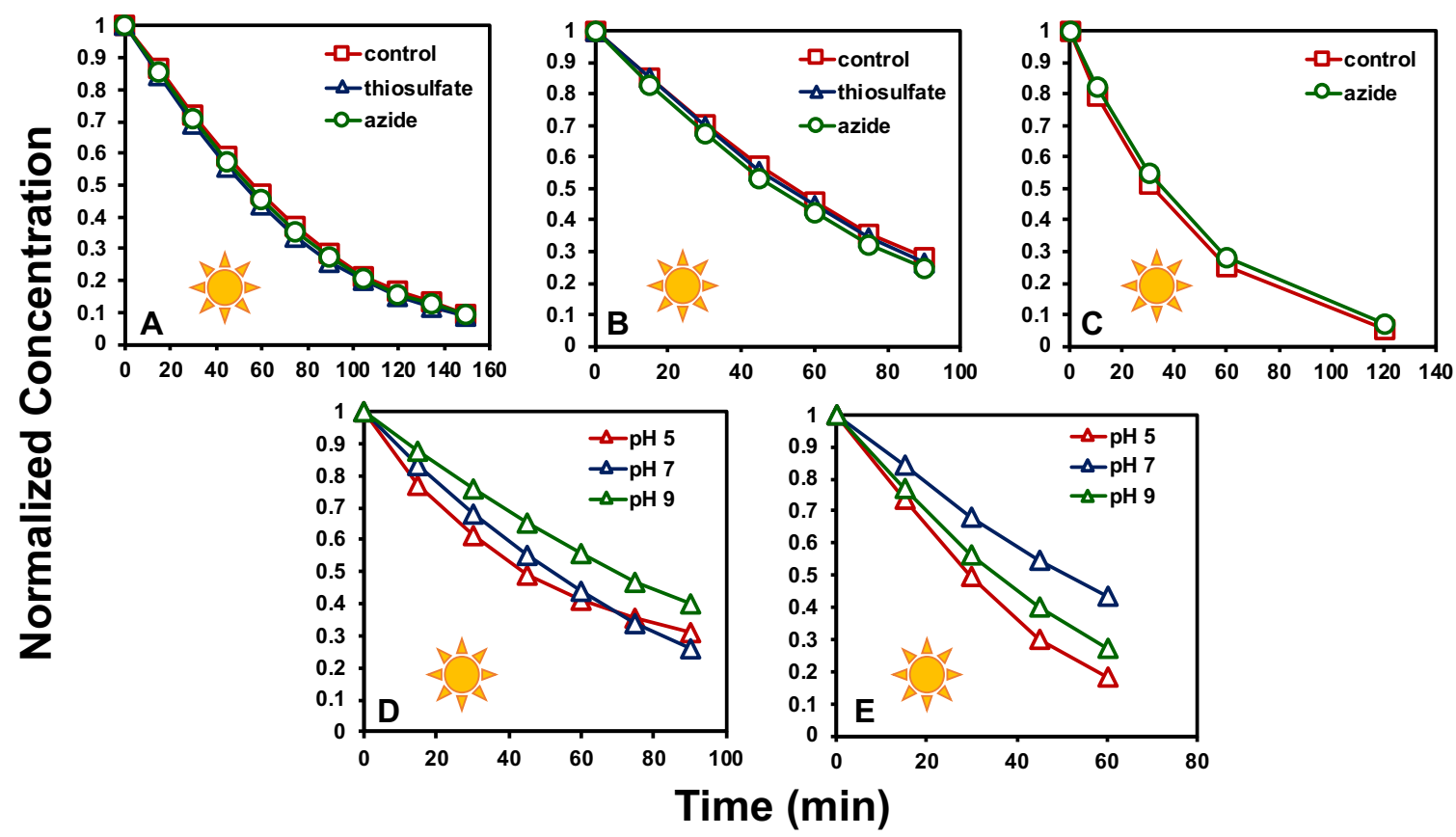

Figure S2. Concentration ( $25 \mu \mathrm{M}$ initial or $\sim 7 \mathrm{mg} / \mathrm{L}$ ) of (A) $17 \alpha-\mathrm{TBOH}$, (B) $17 \beta-\mathrm{TBOH}$, and $(\mathrm{C})$ TBO over time during irradiation with simulated sunlight with or without the presence of nucleophile (1-5 mM) in direct photolysis experiments at $\mathrm{pH}$ 7. Effect of $\mathrm{pH}$ on the concentration of (D) $17 \alpha-\mathrm{TBOH}$ and (E) $17 \beta-\mathrm{TBOH}$ over time during photolysis in the presence of $1 \mathrm{mM}$ sodium thiosulfate. 

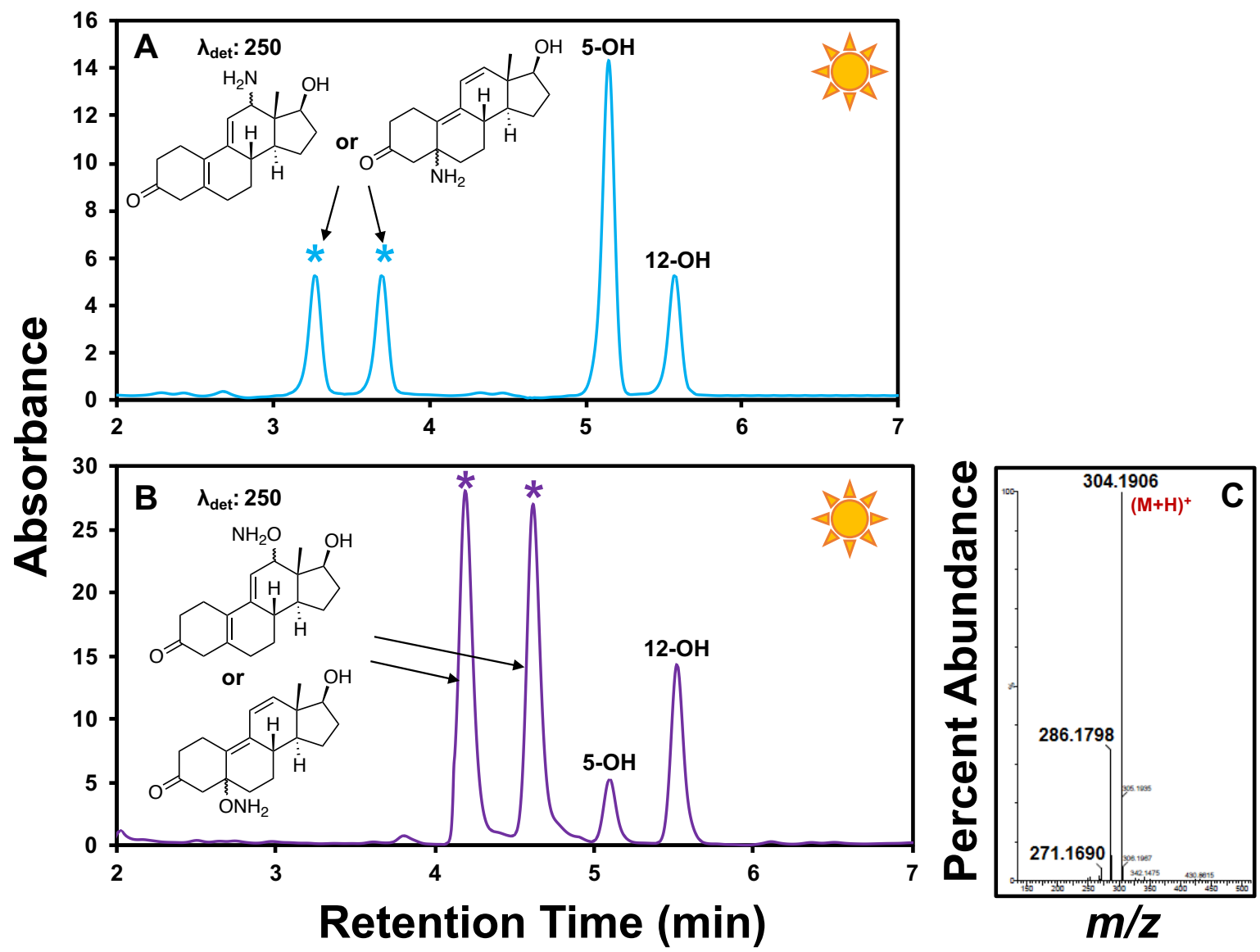

Figure S3. LC-DAD trace of (A) a photoproduct mixture generated at $\mathrm{pH} 9$ after irradiation of $17 \beta-\mathrm{TBOH}$ in the presence of $1 \mathrm{mM}$ ammonia for $90 \mathrm{~min}\left(\lambda_{\operatorname{det}} 250 \mathrm{~nm}\right)$, and (B) a photoproduct mixture generated at $\mathrm{pH} 9$ after irradiation of $17 \beta-\mathrm{TBOH}$ in the presence of 1 $\mathrm{mM}$ hydroxylamine for $90 \mathrm{~min}\left(\lambda_{\operatorname{det}} 250 \mathrm{~nm}\right) .{ }^{*}$ Denotes peaks associated with suspected nucleophilic addition products. Also shown is a MS chromatogram $(C)$ of one of the two suspected hydroxylamine addition products. 


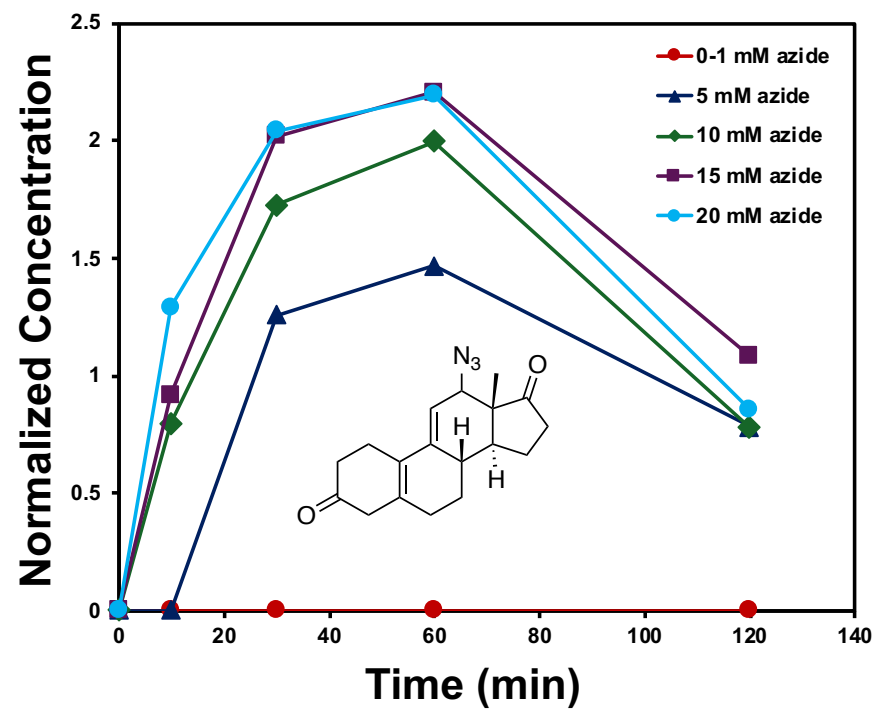

Figure S4. Concentration of TBO azide addition product as a function of time of TBO irradiation in the presence of $0-20 \mathrm{mM}$ azide.

A: $17 \beta-T B O H$, ammonia, $\mathrm{pH} 9$

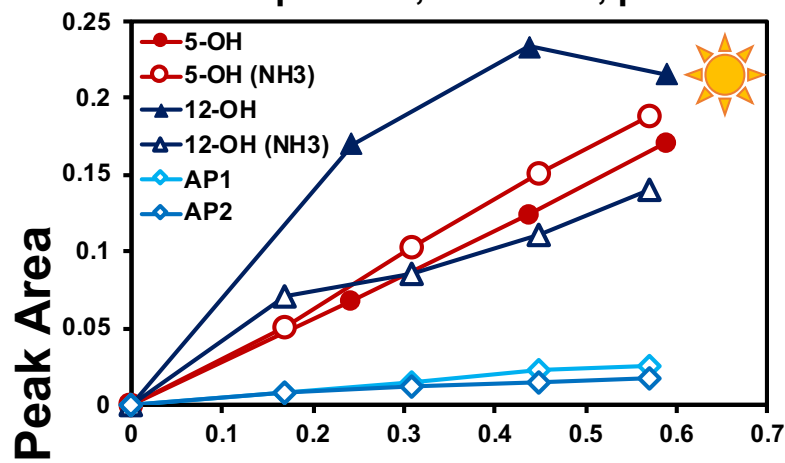

C: $17 \alpha-\mathrm{TBOH}$, azide, $\mathrm{pH} 7$

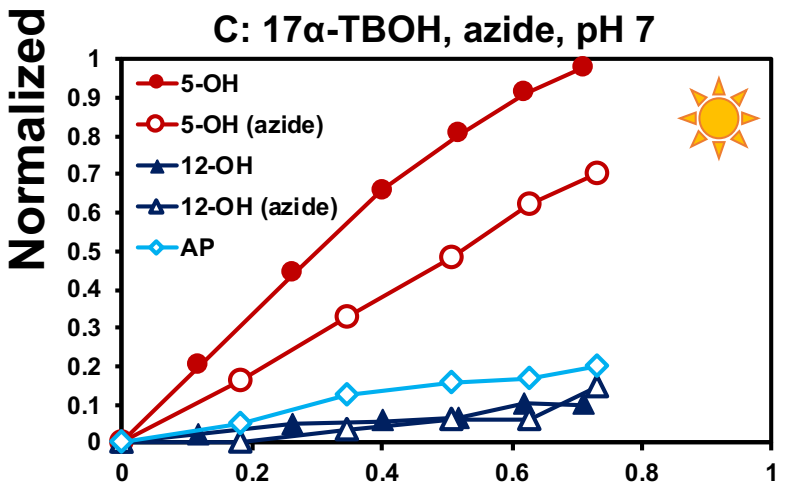

B: $17 \beta-\mathrm{TBOH}$, hydroxylamine, $\mathrm{pH} 9$

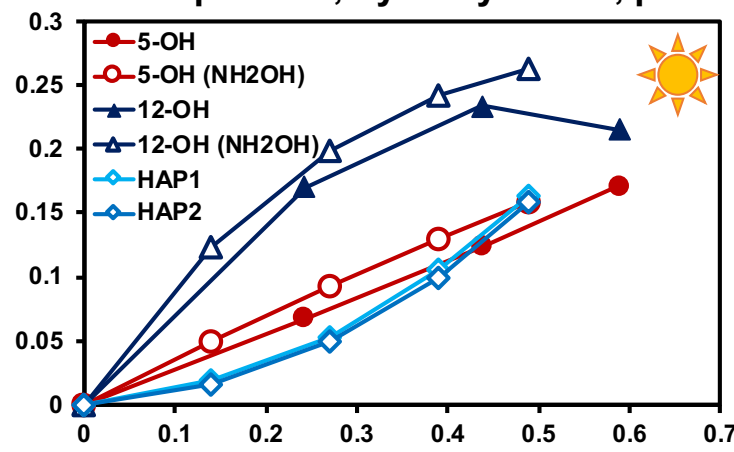

D: TBO, azide, $\mathrm{pH} 7$

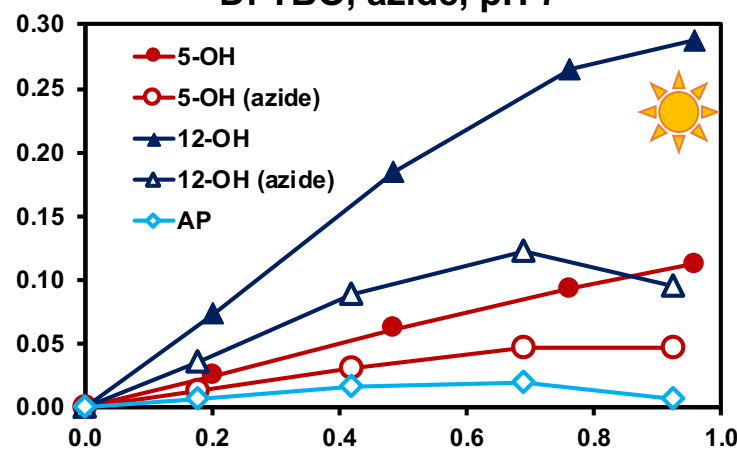

Fractional TBA Metabolite Conversion

Figure S5. Product distribution as a function of fractional conversion of (A \& B) $17 \beta-\mathrm{TBOH}$ at $\mathrm{pH} 9,(\mathrm{C}) 17 \alpha-\mathrm{TBOH}$ at $\mathrm{pH} 7$, and (D) TBO at $\mathrm{pH} 7$ with or without ammonia or hydroxylamine (top row) or azide (bottom row) during irradiation. AP and HAP in top row denote ammonia and hydroxylamine products, respectively, while AP in bottom row denotes azide product. 


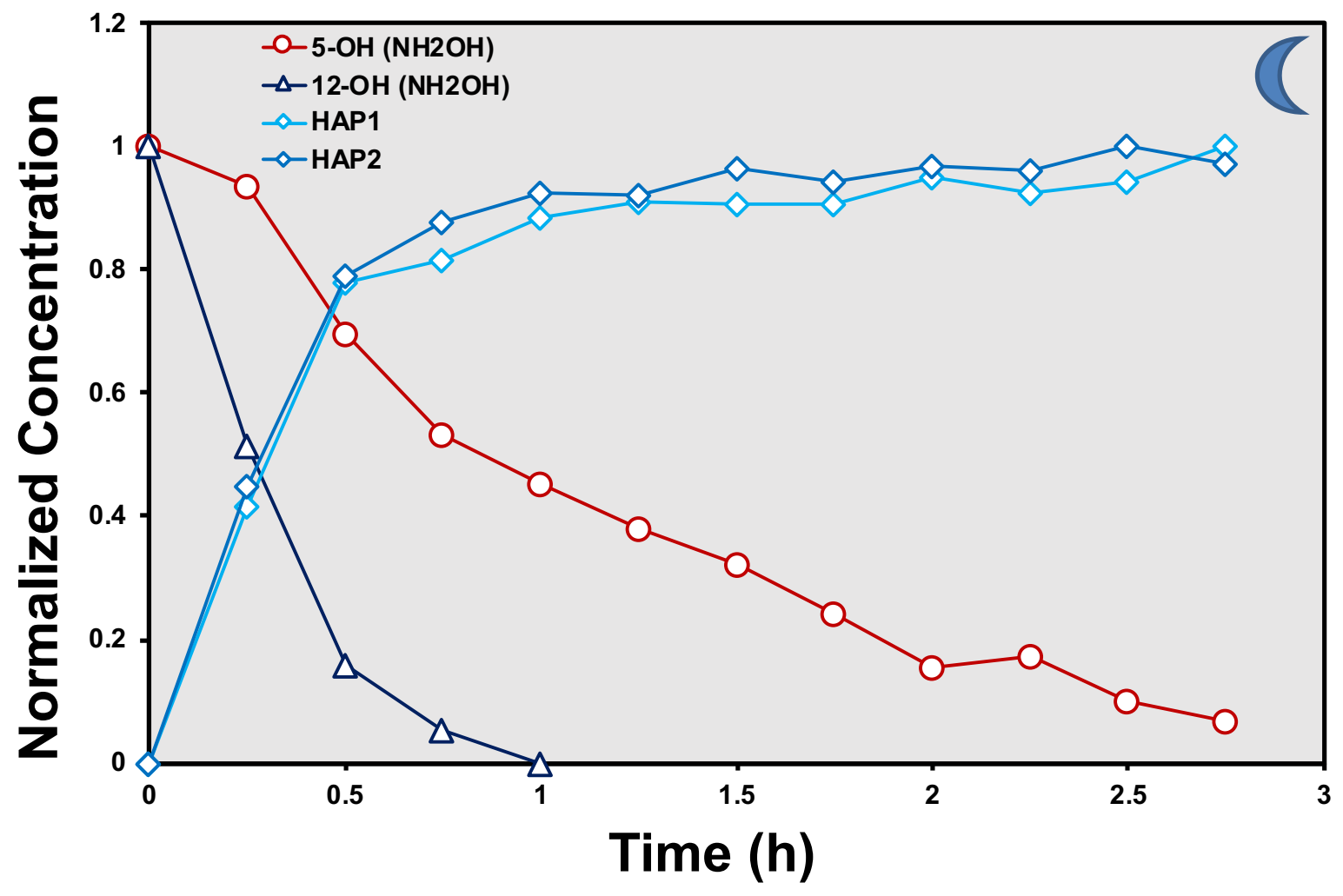

Figure S6. Dark (thermal) stability of 5- and 12-hydroxy-17 $\beta$-TBOH photohydrates generated without the addition of a nucleophile during photolysis at $\mathrm{pH} 7$. Hydroxylamine was spiked at the end of irradiance (i.e., dark time $=0$ ). HAP denotes hydroxylamine products.

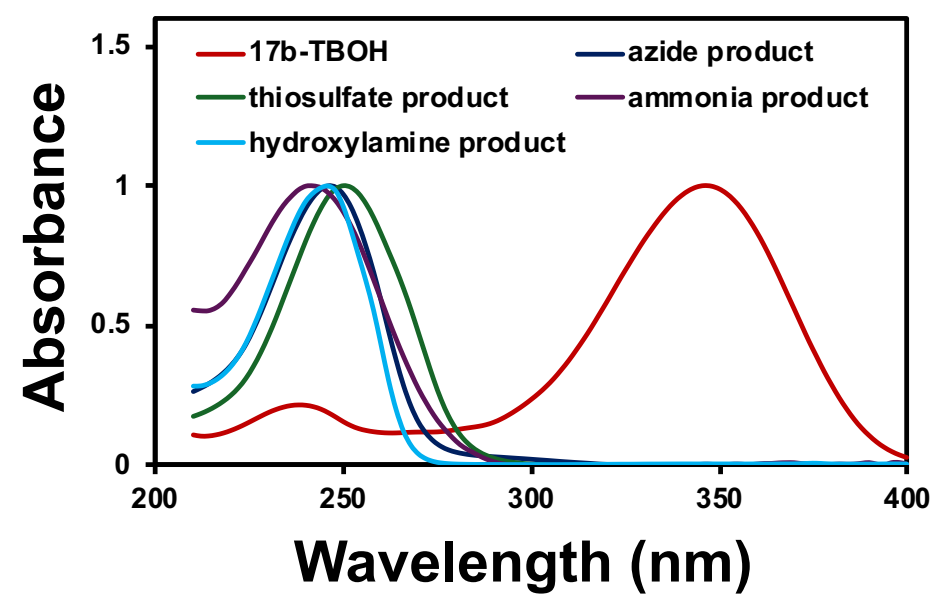

Figure S7. UV spectra of $17 \beta-\mathrm{TBOH}$ and $17 \beta-\mathrm{TBOH}$ nucleophile addition products. 
A: $17 \beta-T B O H$, ammonia, pH 9

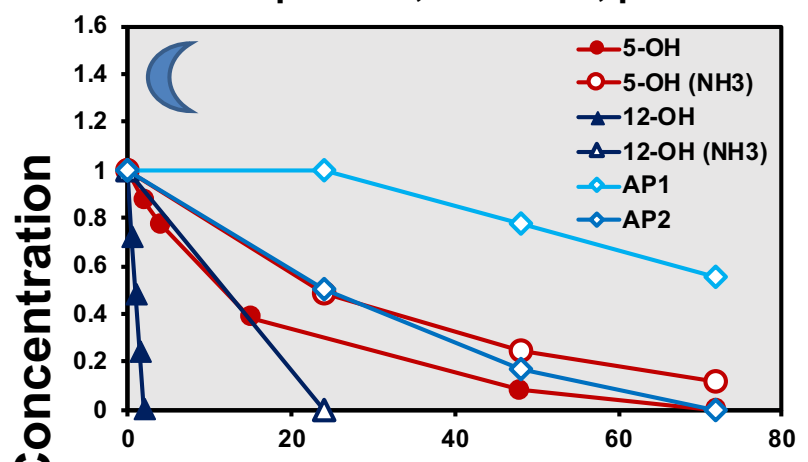

C: TBO, azide, pH 7

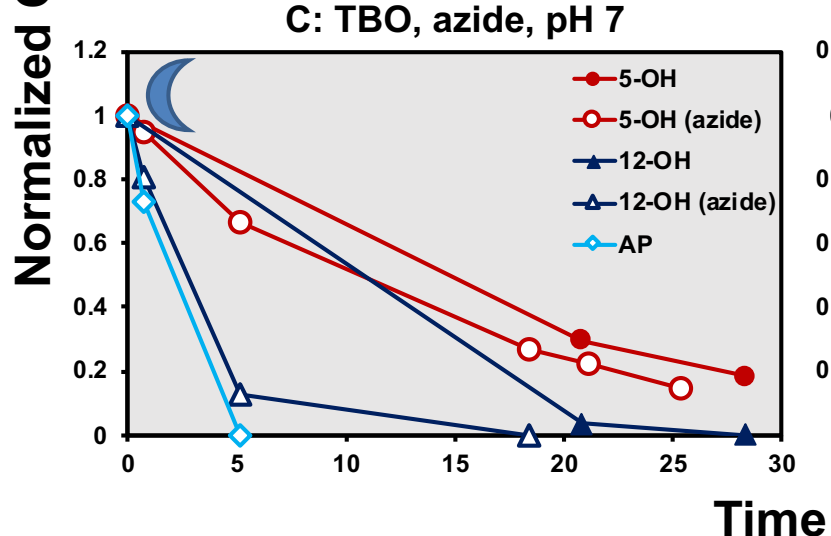

B: $17 \beta-\mathrm{TBOH}$, hydroxylamine, $\mathrm{pH} 9$

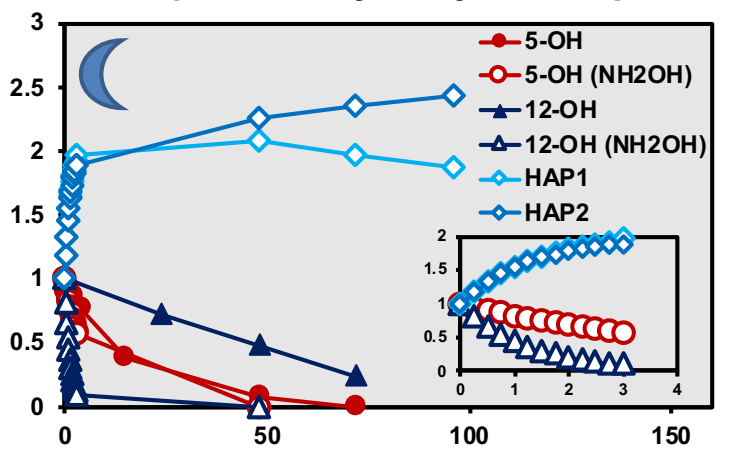

D: TBO regrowth, $\mathrm{pH} 7$

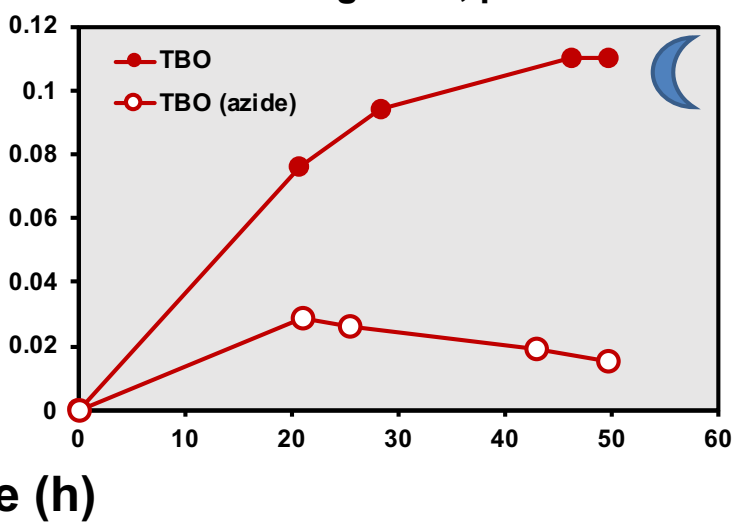

Figure S8. Dark (thermal) stability of 5- and 12-hydroxy-17 $\beta$-TBOH photohydrates with or without (A) ammonia at $\mathrm{pH} 9$ or (B) hydroxylamine at $\mathrm{pH}$ 9. The inset in panel $\mathrm{B}$ is a closeup of the 5- and 12-hydroxy photohydrate decay and the two hydroxylamine products (HAP) formation over the first $3 \mathrm{~h}$. (C) Thermal stability of 5- and 12-hydroxy-TBO photohydrates with or without azide at $\mathrm{pH}$ 7. AP and HAP in top row denote ammonia and hydroxylamine products respectively, while AP in bottom row denotes azide product. (D) Shows dark TBO regrowth after photolysis at $\mathrm{pH} 7$ with or without azide. Concentration of TBO was normalized to its initial concentration before irradiation. 

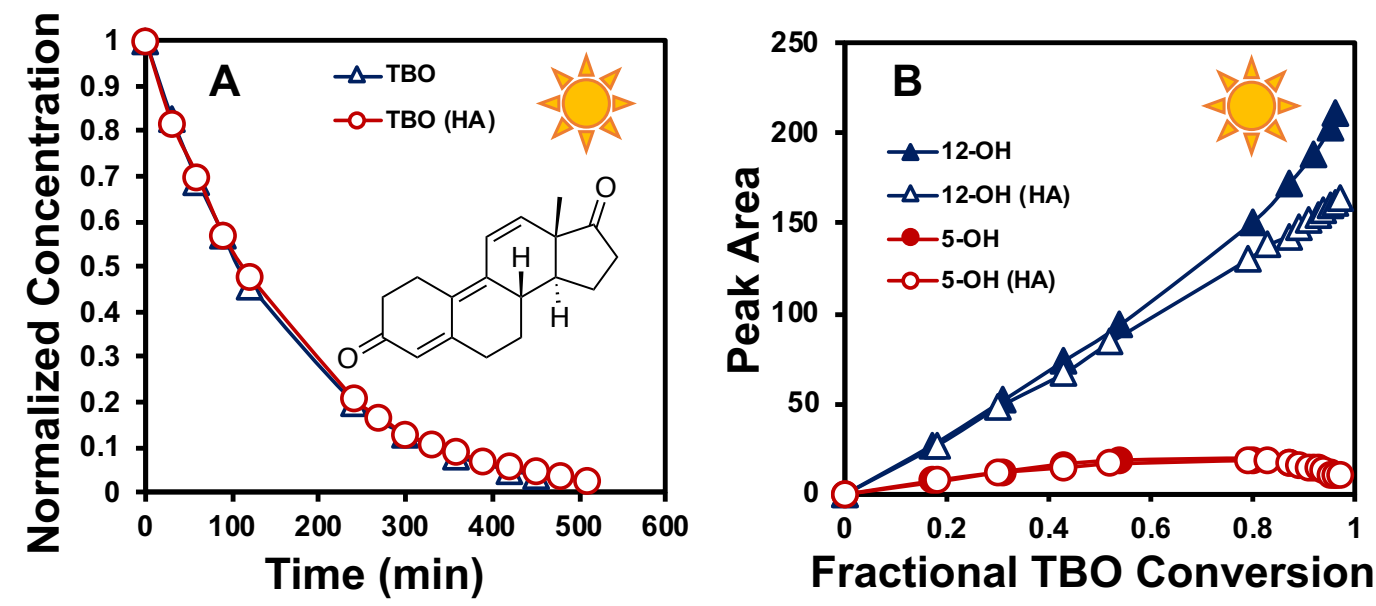

Figure S9. (A) Concentration of TBO $(25 \mu \mathrm{M}$ or $\sim 7 \mathrm{mg} / \mathrm{L})$ over time during irradiation with simulated sunlight with or without the presence of HA $(5 \mathrm{mg} / \mathrm{L})$ at $\mathrm{pH} 5$ and $(\mathrm{B})$ product distribution as a function of fractional TBO conversion with or without HA during photolysis at $\mathrm{pH} 5$. 